posed to feel while talking and singing with a piece of red-hot iron attached to his tongue."

Now, Sir, one does not feel much surprised that the extraordinary man whose facetious volubility caused half the town to " crack" their sides with laughter, should in his turn get a "crack" in his tongue; but one cannot fail to remark, 1st, the great sinilarity between the two cases; and, 2ndly, the failure in both of the methodus medendi. I am, Sir, your obedient servant,

23, Upper Seymour-street West, S. Godson, M.D. Connaught-square, August 26, 1840.

\section{CASE OF SEVERE RHEUMATISM CURED BY NATURE.}

\section{To the Editor of The LANCET.}

Sir :-I beg to send you some statements under the above head. Much benefit would, in my opinion, accrue to medical men, if patients themselves more frequently laid before the public a statement of the effect upon them of medicines administered to them, and of the efforts of nature to restore them to health. It is from this conviction that $I$ beg to explain here the mode in which $I$ have recovered from a violent rheumatism.

During the winter of $1838.9, I$ was, for the greater part of the day, engaged in writing, and being generally very sensible to draughts of air, I took, indeed, care to keep the win. dows and the doors of my sitting-room shut; they closed, however, not quite, as is the case in the generality of the houses in London, and being obliged, for having a fire, to remove the chimney-board, there was al ways some draught in my room; in addition, a general draught was kept up in the house in which $I$ then resided, and the whole site of it, Covent.garden Colonnade, was itself much exposed to draughts of air, as six or eight streets and lanes open on it. The whole of the day, when $I$ was writing, the draught of air passed by my left side, and at the end of the winter I felt some difficulty in walking, but thought it would go off by itself, and took no medicine. In the ensuing spring, however, and summer of $1839, \mathrm{my}$ complaint increased, when it became clear that nature could not cure it, unless assisted by external or internal medicines, or a change of my residence. When I next took the advice of medical gentlemen; one deem. ed an aperient necessary, the other an em. brocation. To an aperient $I$ objected, ny complaint being of six months' standing, and having been in this manner ulmost incorporated in the system; in fact, German physicians never administer aperients in chronic diseases, as one or two would, at all events, not be sufficient, and a protracted treatment of this kind could only tend to delay the recovery of a patient. I then resorted to the embrocation prescribed for me, and con. sisting of a camphorate ointment; I rubbed with it the left hip and thigh, also the extremities of the left ribs; but though it first seemed to relieve me, it finally increased the difficulty which I found in walking, and the soreness of the region of the extreme left ribs. Probably the embrocation, which 1 continued for upwards of a month, was too strong for me, ammonia being added; I re. member also having read in Germany, in 2 medical journal, that it was a prevalent error to suppose that rhe u matic swelling of cheeks could be cured by the application of cushions flled with camphor, which rather protracted the evil, as the camphor more con. densed the rheumatic substances than dis. persed them. A milder embrocation of opodel. doc seemed at first to have a good effect ou my complaint; but it was of too long stand. ing to be cured by external means only. The principal difficulty was to get rid of what the modern medical school of Hahnemann now calls by a word from the Greek, "the psora,"i.e., the injurious matter affecting the internal parts and causing the illness; in my case the psora was the diseased rheumatic matter inducing a partial lameness of the muscles, on which walking depends, so as to create difficulty in walking, and soreness of the parts over the left hip. Now, in this country, they put great confidence in colchicum, whose use is in Germany more contined to gout ; it was, consequently, administered also to me, but weakened me generally, and my knees particularly, so that $I$ discontinued the pills in which it was made up, after baving taken them for upwards of six weeks, and never experienced any benefit from them.

A bout this time I saw in a London paper an article, the author of which stated, that aconite was in Germany now much administered in rheumatisms, and that he himself a graduate in medicine, who also gave his name, had cured a desperate case of this kind, by prescribing "extract of aconite a quarter of a grain twice a.day, gradually increased to six grains per day, to be taken with ten grains of Dover's powder." I began with Dover's powder, which I found to have a general invigorating effect, without particularly acting on my complaint. Of the aconite $I$ then took in pills a quarter of a grain once a-day, but not twice, neither increasing the doses. This I found to strengthen the muscles, and I at one momeut thought I should entirely recover by it. I continued these pills for about six weeks, and might then have left the remainder to nature, and the after effect of the pills. Because, however, in the London paper, a medical practitioner had stated that six grains might be taken per day, I thought there wonld be no harm in continuing to take half a grain per day. No sooner had I taken this quantity on two 
successive days, when, probally by overirritation, the former weakness of the knees and difficulty in walking returned.

I now resolved on leaving my case to nature to cure it; but to assist nafure by a change of the air, and by choosing another lodging. Having had for some months the benefit of not being so much as before exposed to draught of air, nature began the work of cure, and first I had a good deal of sneezing. Supposing that it would be advisable to support nature in this effort, I took from time to time a few pinches of snuff; but the sneezing, as $I$ now consider it, was the effect of an effort previonsly made by nature in the clearing of the internal system; and though it might itself also contribute to my recovery, still, from forcing it, I had no benefit. After having sneezed several weeks together, I had at night a good deal of perspiration over the hips, which caused me to resume my former embrocation of opodeldoc, and to rub it in exactly in the parts mentioned. Lastly, nature having become entirely master of the psora, and dispersed it, I got a cough, with moderate expectoration, which lasted for several weeks; and when it ceased $I$ was as well as I could wish, and walk now as freely as I ever did before.

Rheumatisms are of frequent occurrence in this country; but the mode of their treatment should perhaps undergo some alteration. Colchicum should be totally excluded; but nothing is more beneficial in sicknesses of this kind, than to have the benefit of the morning sun, and to be attentive to the operations of nature. If I had disturbed nature when $I$ first began to sneeze, and at last to cough, my complaint would probably not yet have been removed. As to aconite, I should, from my experience, say, that six grains per day would consign many persons to their graves; but all to their beds for a long time. I am, Sir, your obedient servant,

John von HoRn, D.D., of Göttingen.

12, York-street, Covent-garden, August 24, 1840.

** The above letter is a curiosity, and well exemplifies the adage, "A little knowledge," \&c. The writer is evidently one of those self-willed persons who in a serious case would impede their own cure, by assuming an opinion opposed to that resulting from the careful study and knowledge of disease. In the last paragraph the author ventures upon a little advice, which, in consideration of his D.D.'ship, will be received by the profession with a smile. To the unlearned such persons are extremely dangerous; but we trust that the love of life will induce the afflicted to seek, on all occa- sions of disease, that assistance and advice which can be conferred with advantage only by those who have carefully cultivated medical science.

\section{COPY OF MINUTES \\ OF \\ POOR-LAW COMMISSIONERS, \\ Dated Augrist 20, 1840.}

Minute of Instructions to be issued with respect to the Preparation of Contracts for the Extension of Vaccination.

Contracts must be made under the Act to extend the practice of vaccination, in order to carry its provisions into effect in every place in England and Wales maintaining its own poor, whether such place be included in a union or not, and whether known by the name of parish, township, or vil, or by any other designation whatsoever. The officers, who are immediately invested with the duty of making contracts, are the guardians of the poor in parishes, unions, and incorporations, in which relief to the poor is administered by guardians, and other officers having similar functions to those of guardians, but having different names of office, such as visitors, governors, directors, managers of the poor; and where there are no such guardians or other officers, then the overseers of the poor. The extension of the provisions of the Act to all places maintaining their own poor, and to all the officers besides guardians and overseers, is an effect of the ninth clause in the Act, by which the like meaning is given to the terms used in the Act, as is given to the terms used in the Poor-Law $\Lambda$ mendment Act.

The Act is generally to be carried into effect under the direction of the Poor-Law Commissioners. But the Commissioners prefer to leave, as far as may be possible, the introduction of the measure to the voluntary action of the local officers, and they will not issue compulsory orders except in cases where the provisions of the Act would otherwise fail of having their due effect given to them.

The first duty of the guardians and other local officers, $w$ ill be to take into consideration the circumstances of the district, the number of persons who will probably require to be vaccinated at the commencement of the measure, and the probable average in succeeding periods. These considerations will enable them to come to a determination on the following points :-

1. The number and extent of the districts, and the number of the persons to be contracted with.

The guardiaus not being limited to the medical officers of the union, may make these as numerous as they think desirable; 